NASZA DERMATOLOGIA Onlin OUR DERMATOLOGY Online

Source of Support: Nil

Competing Interests: None

\section{UNGUAL DYSCHROMIA}

\section{Patricia Chang}

Dermatologist at Hospital General de Enfermedades IGSS and Hospital Ángeles, Guatemala

Corresponding author: Patricia Chang, $\mathrm{MD} \mathrm{PhD}$

pchang2622@gmail.com
Nails can has different color it may be called ungual dyschromia or chromonychia that means abnormalities in color of the substance.

The transparency of the nail it's important for dyschromia, the pigment may accumulate due to overproduction such as melanin, storage as copper, haemosiderin, drugs, or by surface deposition [1].

Ungual dyschromia may be endogenous and exogenous if the pigment is due to endogenous source the discoloration corresponds to the shape of the lunula (Fig. 1) and if it exogenous corresponds to the contour of the proximal nail fold (Fig. 2). Dyschromia can affect one, several or twenty nails depends of the cause that may be congenital, dermatological, drug side effect, trauma, systemic diseases, miscellaneous, benign and malignant tumors, infectious diseases, others.

Nail dyschromia may be white, black, green brown, yellow, red, and blue, gray, purple and others, but the most common are white and black.

The white color is called leukonychia and the black discoloration is called melanonychia.

There are three types of leuconychia: true leukonychia, pseudoleuconychia and apparent leuconychia. True leukonychia, the nail plate involvement source is in the matrix, may be partial such as transverse (Fig. 3), punctate (Fig. 4), lineal (Fig. $5)$ or total, in pseudoleukonychia the matrix is not affected example white superficial onychomycosis (Fig. 6, 7) and apparent leukonychia is called also apparent leukopathia with involvement of the subungual tissue, subungual kyperkeratosis, (Fig. 8), onycholysis (Fig. 9, 10), apparent leukopathia such as Terry's nail (Fig. 11) associated to cirrhosis, half $\&$ half nails with chronic renal failure (Fig. 12, 13), Muehrcke's bands due

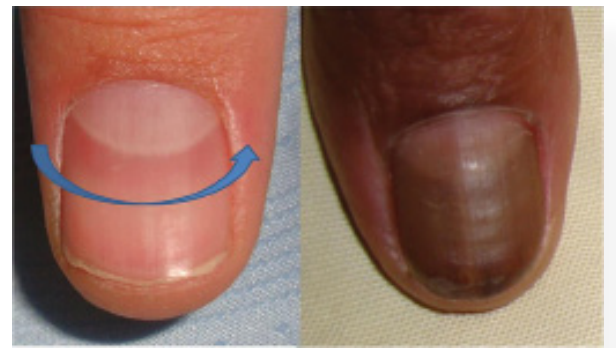

Figure 1. Endogenous cause of dyschromia, discoloration tends to follow the countor of the lunula. to hypoproteinemia and cytostatics drugs (Fig. 14) and anemia. Melanonychia may be longitudinal, transverse, total can affect fingernails and feet within its causes have to melanonychia racial (Fig. 15), idiopathic Addison's disease (Fig. 16), drugs such as cytostatics (Fig. 17, 18), retinoids such melanonychia together with the onychomadesis, onycholysis and periungual pyogenic granulomas are the most common drug nail disease [2], puvaterapia, lichen planus, infections by bacteria, fungi, trauma frictional melanonychia (Fig. 19), carpal tunnel syndrome tumors such as basal cell carcinoma, squamous and melanoma can manifest as a longitudinal melanonychia which may be the first manifestation of the same [3] is very important to consider the A, B, C, D, E, F of injury.

The green nail can be caused by Pseudomona (Fig. 20) and Candida infections, the yellow color can be seen in the yellow nail syndrome (Fig. 21), onychomycosis (Fig. 22), dye shoes (Fig. 23), jaundice, cyanosis blue (Fig. 24) be related to hypoxia, argiria, the orange nail polish, the hair dyes (Fig. 25), coffee, smoking (Fig. 26), potassium permanganate, gentian violet (Fig. 27), nevi, racial, Laugier syndrome-Hunzinker-Baran, malnutrition, pregnancy, red for subungual nail hematoma (Fig. 28), splinter hemorrhages (Fig. 29), paint, red lunula (Fig. 30) is associated cardiopulmonary disorders, collagen diseases, malignancies hematologic, alopecia areata, psoriasis, trauma, idiopathic longitudinal view erytronychia Bowen's disease and other, red purpuric may be associated with drugs such as clofazimine, heparin, warfarin, capecitabine, puvaterapia, polycythemia and some glomus tumor vascular tumors, trauma (Fig. 31) [4,5]. Nails can have one, two or three color in the same nail and for different causes.

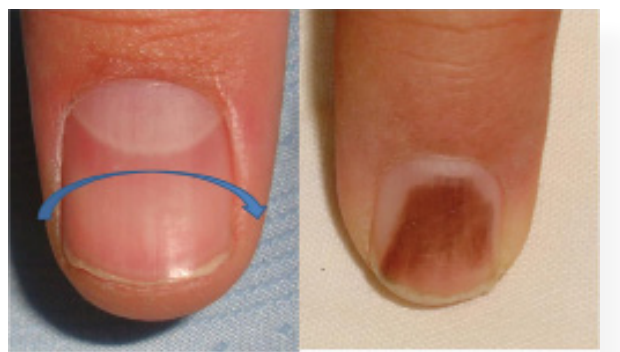

Figure 2. Exogenous cause of dyschromia, discoloration tends to follow the contour of the proximal nail fold. 


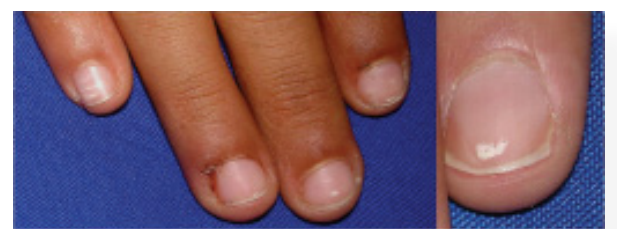

Figure 3. Leukonychia Transverse.

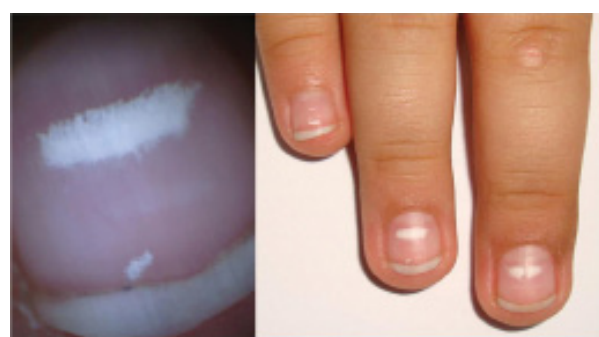

Figure 4. Leukonychia puntata.

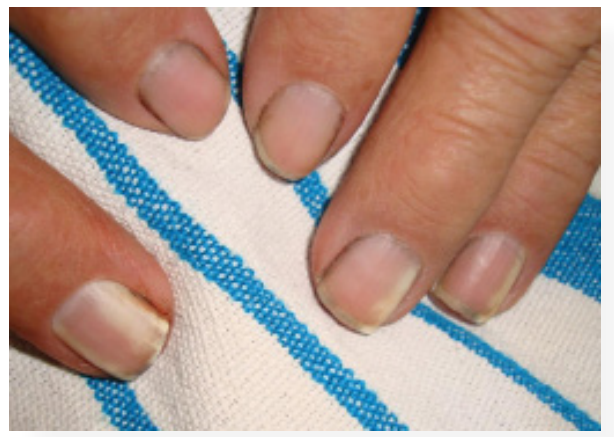

Figure 5. Leukonychia lineal.

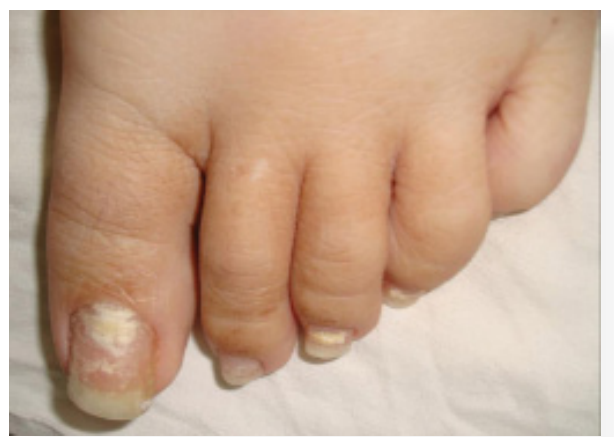

Figure 6. White superficial onychomycosis.

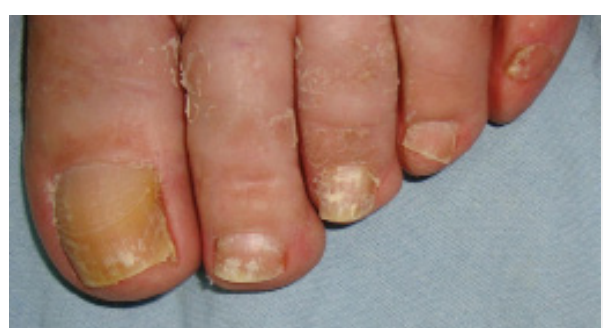

Figure 7. White superficial onychomycosis.

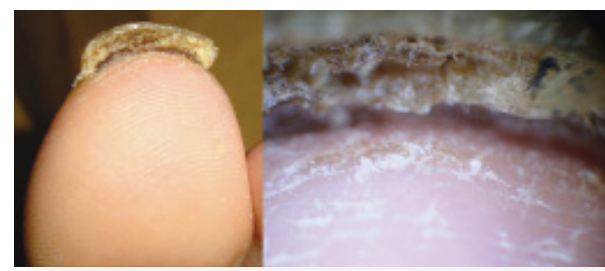

Figure 8. Subungual hyperkeratosis.

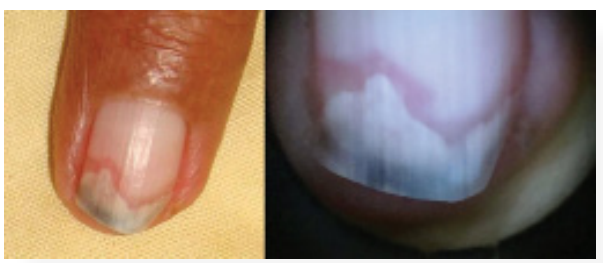

Figure 9. Traumatic onycholysis.

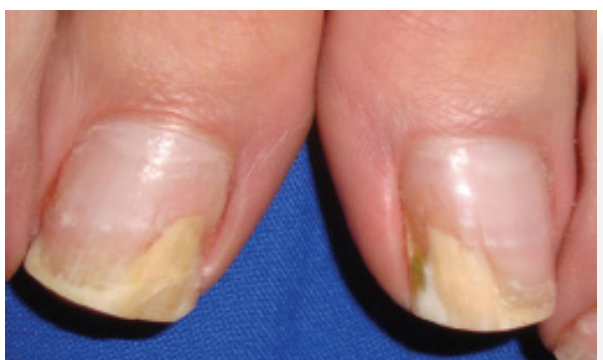

Figure 10. Traumatic onycholysis.

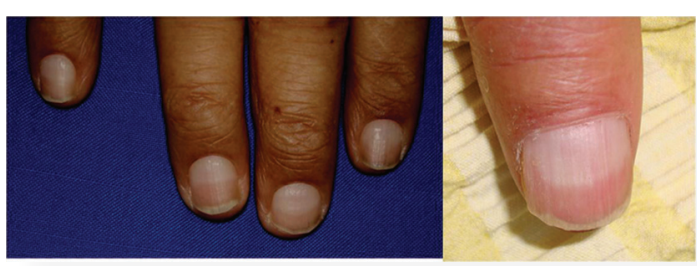

Figure 11. Nails half and half associated to chronic renal failure.

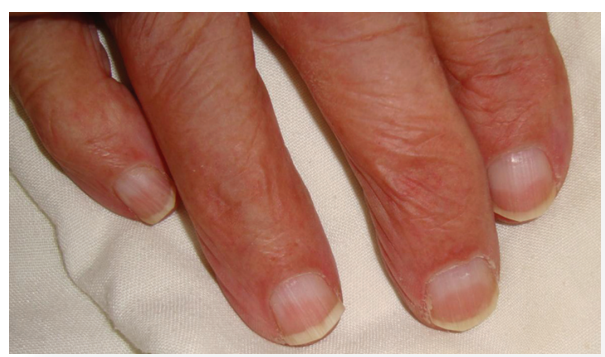

Figure 12. Nails half and half associated to chronic renal failure.

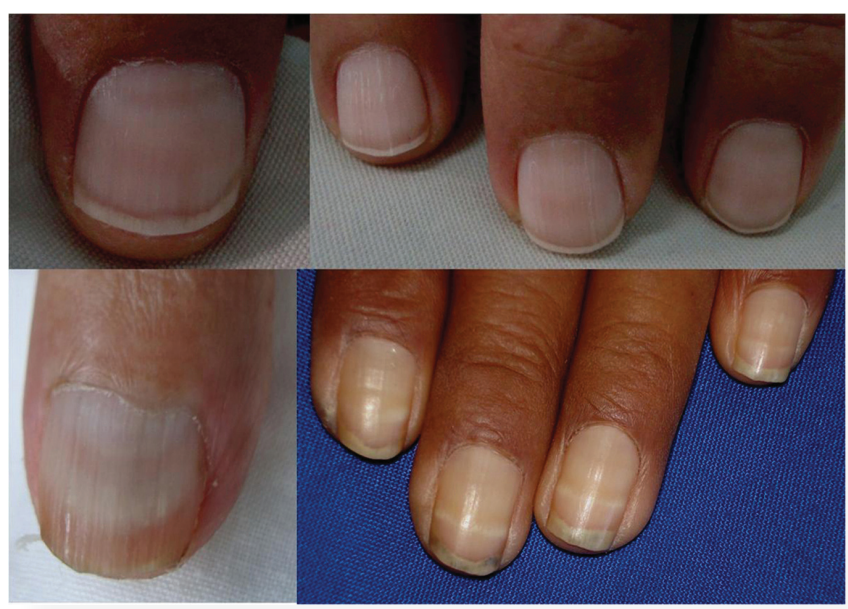

Figure 13. Muehrcke's bands due to hypoproteinemia and cytostatic drugs. 


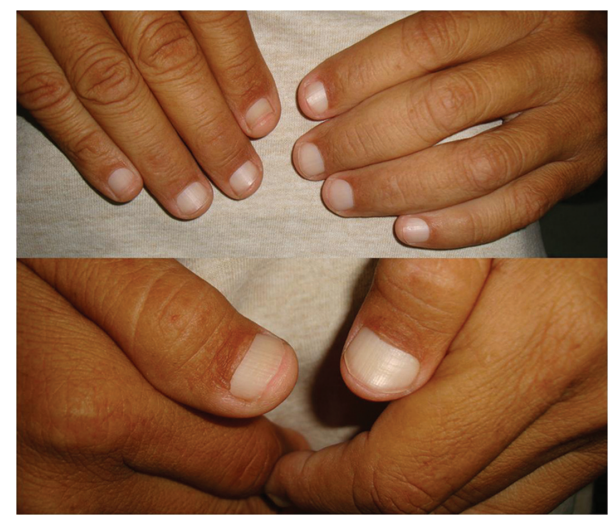

Figure 14. Apparent leukopatia due to anemia.

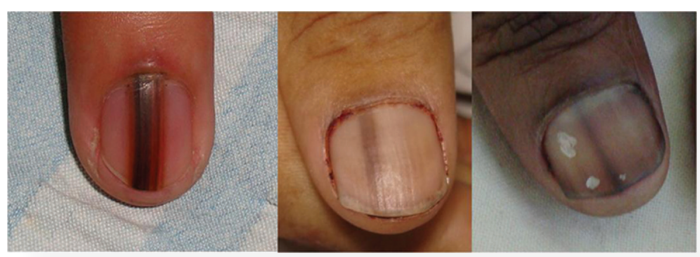

Figure 15. Racial melanonychia.

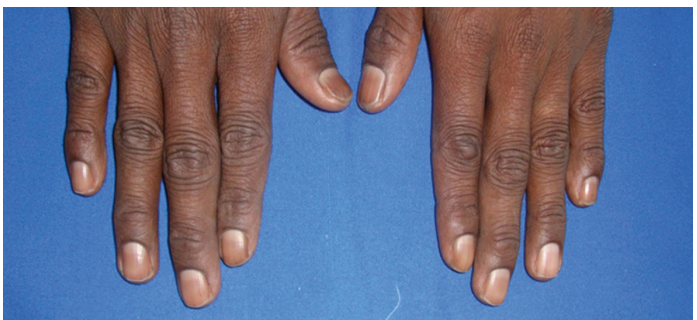

Figure 16. Melanonychia due to Addison's disease.

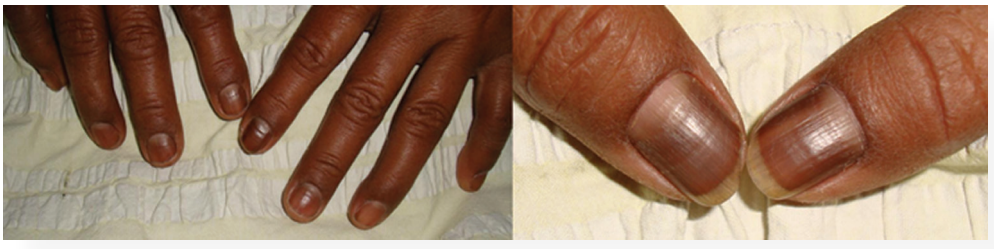

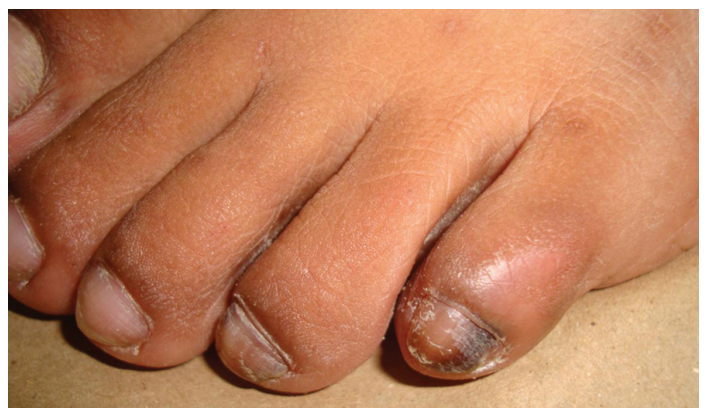

Figure 19. Melanonychia frictional.

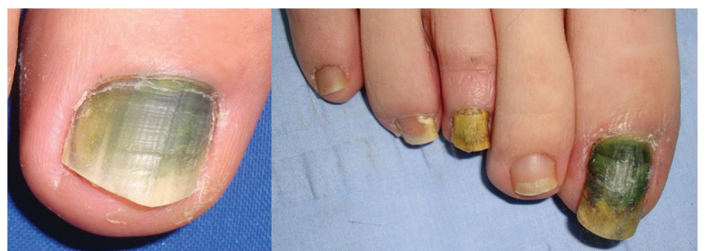

Figure 20. Green color due to pseudomona infection.

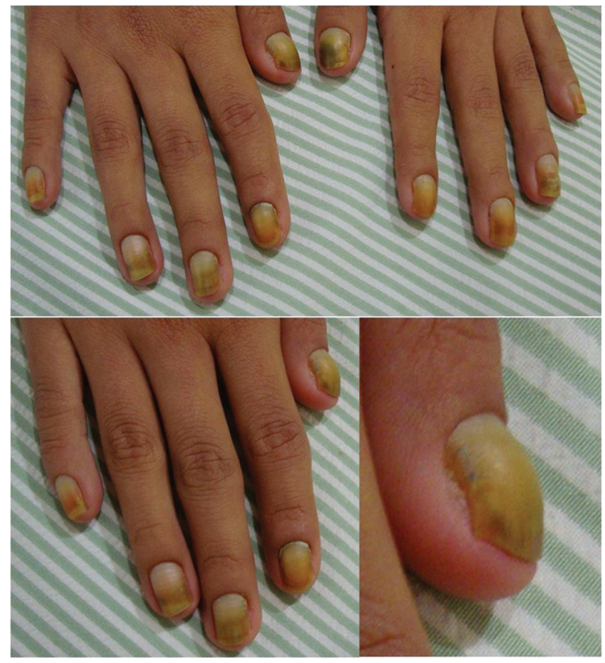

Figure 21. Yellow nail syndrome.

Figure 17. Melanonychia due to cytostatics drugs.

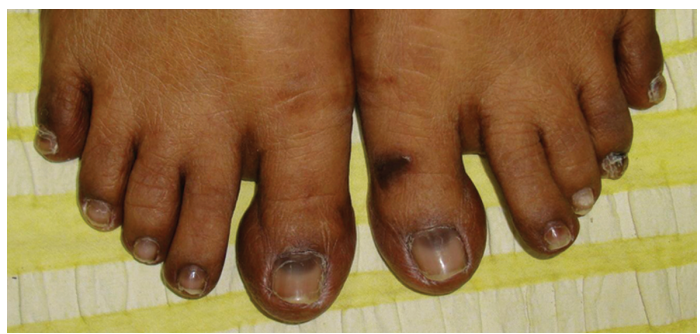

Figure 18. Melanonychia due to cytostatics drugs.

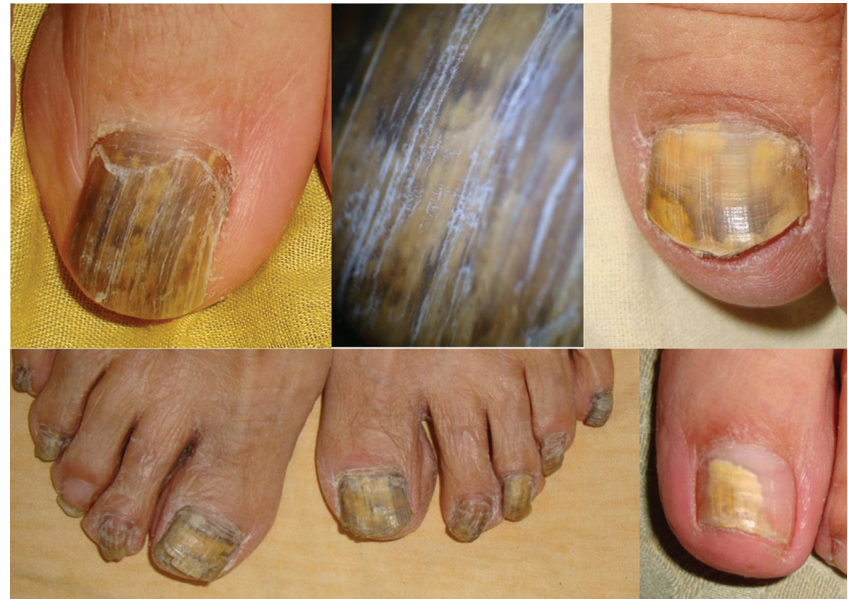

Figure 22. Onychomycosis. 


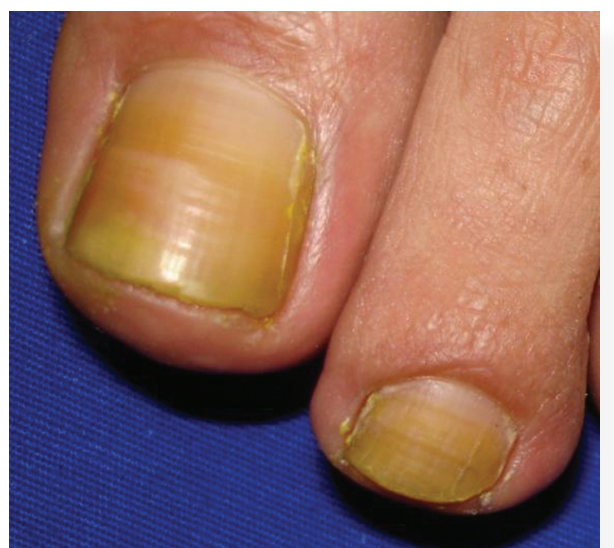

Figure 23. Yellow nails due to shoe dye.

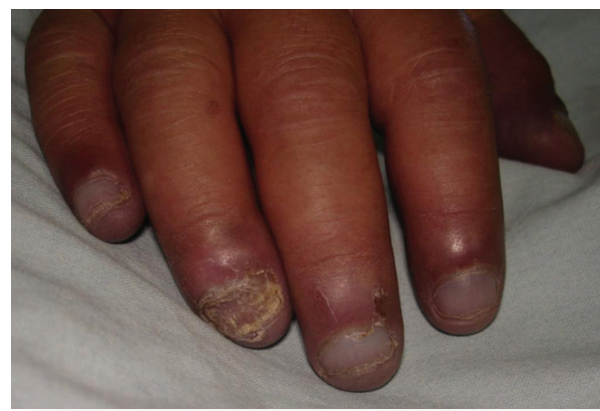

Figure 24. Acrocianosis due to sepsis.

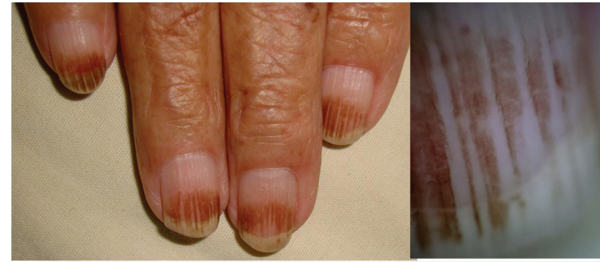

Figure 25. Dye hair.

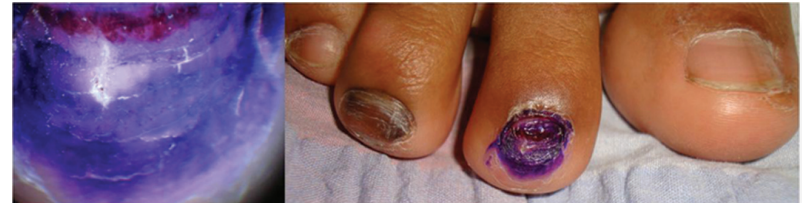

Figure 26. Dyschormia gentiant violet dye.

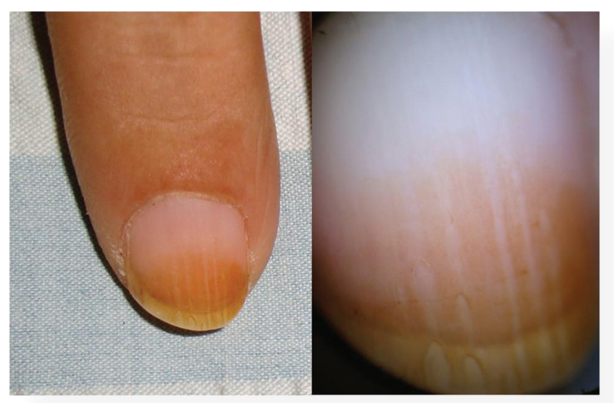

Figure 27. Dyschromia due to tabaco.

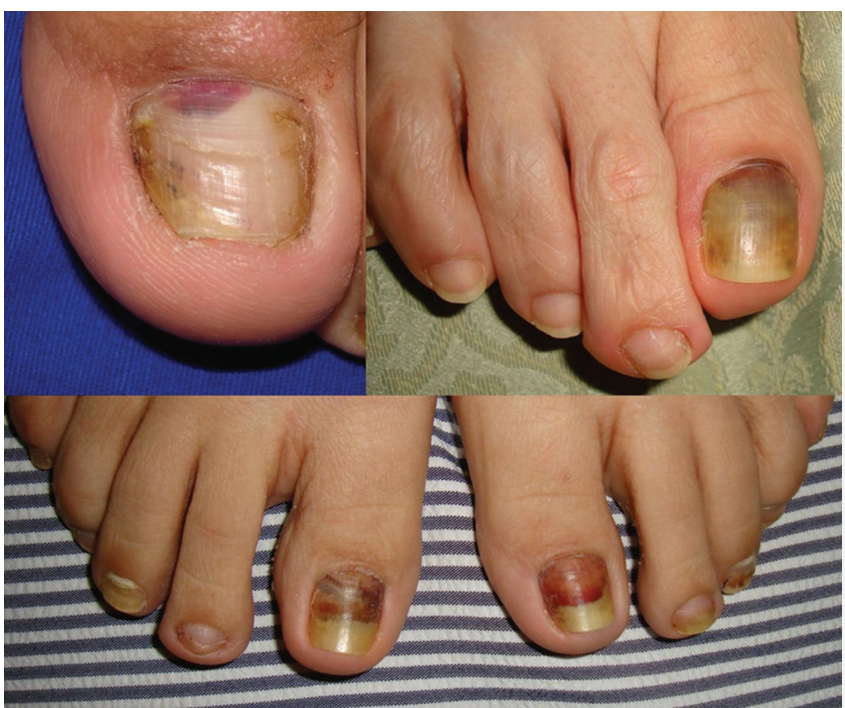

Figure 28. Red color due to hematoma.

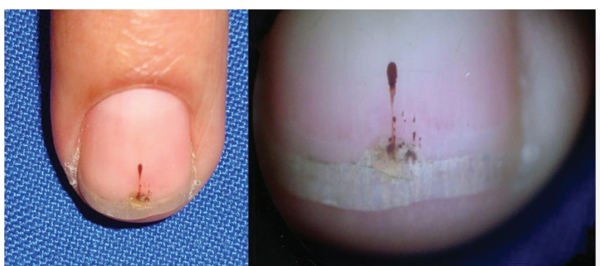

Figure 29. Trauma.

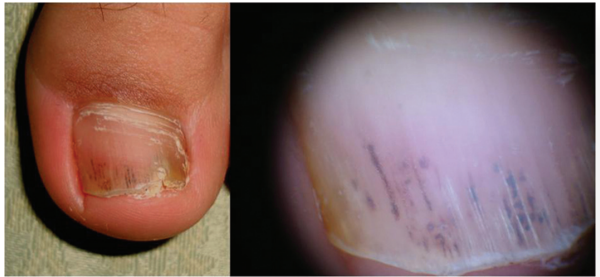

Figure 30. Splinter hemorraghe.

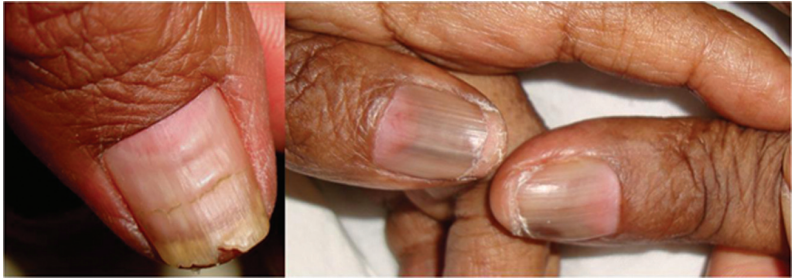

Figure 31. Red lunula.

\section{REFERENCES}

1. Baran R: Pigmentations of the nails (chromonychia). Dermatol Surg Oncol. 1978;4:250-4.

2. Piraccini BM, Iorizzo M, Antonucci A, Tosti A: Drug-induced nail abnormalities. Expert Opin Drug Saf. 2004;3:57-65.

3. André J, Lateur N: Pigmented Nail Disorders Dermatol Clin. 2006;24:329-39.

4. Baran R, Dawber R, Haneke E, Tosti A: A text Atlas of nail disorders. Diagnosis and Treatment. Martin Dunitz. London. 2001:138,151.

5. Baran R, Haneke E: The nail in Differential Diagnosis Informa healthcare UK 2007: 89, 98, 99,101,103.

Copyright by Patricia Chang. This is an open access article distributed under the terms of the Creative Commons Attribution License, which permits unrestricted use, distribution, and reproduction in any medium, provided the original author and source are credited. 